\title{
BRAINSTORMING THE CRYOPLANE LAYOUT BY USING THE ITERATIVE AHP-QFD-AHP APPROACH
}

\author{
Caglar UCLER \\ School of Aviation, Ozyegin University, 34794 Istanbul, Turkey \\ E-mail: caglar.ucler@ozyegin.edu.tr
}

Received 12 November 2015; accepted 15 June 2017

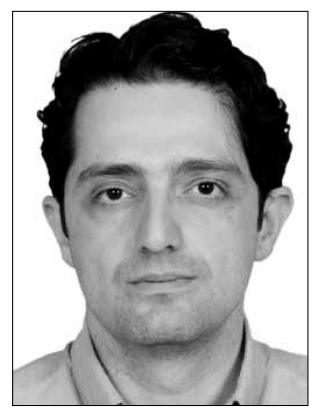

\section{Caglar UCLER, Dr Eng.}

He graduated from the Technical University of Munich (TUM) and was awarded a diploma in Mechanical and Aerospace Engineering and finished his PhD in Concurrent Engineering at Marmara University. For over 15 years, he has worked in several international industrial projects in aerospace and defence, mainly focusing on $R \& D$, design management, CAE and/or cryogenics. He is currently a faculty member in the School of Aviation at Ozyegin University and freelance consultant focusing on new product development and technology management.

\begin{abstract}
Most of commercial civil aircraft are derivatives of each other. They start with an aero-structural design based on the mission profile, and what remains is the integration of existing subsystems. This only leaves room for incremental innovation. When a totally new concept has to be worked out, an innovative brainstorming procedure has to be facilitated, leading to a new product definition. This collaborative creative thinking is not an easy task, and analytical design management tools are required. Therefore, an iterative AHP-QFD-AHP approach for brainstorming is implemented into a concurrent engineering environment in the early phases of layout conception. In the case study, the proposed model delivered the product definition of the cryoplane concept successfully, which promises clean operation. plane.

Keywords: AHP, QFD, concurrent engineering, concept development, new product development (NPD), cryo-
\end{abstract}

\section{Introduction}

On one hand, change is inevitable, so radical technology breakthroughs, which drive towards innovations (Iyer et al. 2006), must be managed to maintain sustainability (Tidd et al. 2005). Higher requirements and limits of old technologies lead to radical innovation, where totally new products are introduced (Borgianni, Rotini 2012). On the other hand, aircraft design is highly constrained by airworthiness regulations (De Florio 2006), delaying or even preventing the generation of collaborative creative concepts.

In order to cope with the regulations and life-cycle issues, aircraft producers, such as Airbus, implement concurrent engineering techniques (Mas et al. 2013). These efforts, however, are mostly introduced within the design gates after the initial product conception that comes after the requirement generation, which is the key for radically new technologies. There are attempts to enable a collaborative environment, such as the Common
Parametric Aircraft Configuration Schema (CPACS), as in DLR (2015), or Conceptual Aircraft Vehicle Engineering CAVE in Safavi (2013). Since they assume existing data bases and models, they are suitable for derivative designs. Digital design tools that are increasingly used (Fixson, Marion 2012) do not support innovative new product design (NPD) in the preliminary phases, so it is still a manual task in a concurrent environment (Ucler 2014a).

Considering that most of the failures in new products are front-end related (Florén, Frishammar 2012), the preliminary stage in the NPD should be carried out using a collaborative analytical approach to include all aspects, ensuring consistency as well as improving efficiency and effectiveness (Leenders et al. 2007). Supervisory analytical tools might negatively impact creativity, which is fundamental for NPD (Tu, 2009). NPD is driven by the communication structure of the team (Leenders et al. 2007), which also supports creativity, 


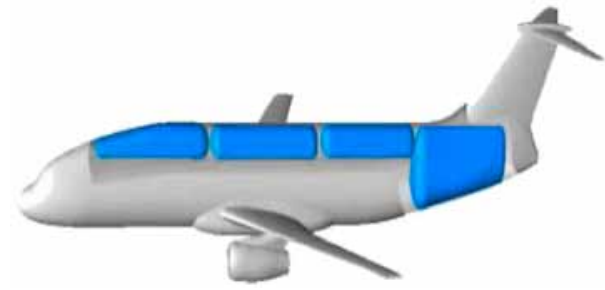

Fig. 1. Traditional cryogenic plane layout in Khandelwal et al. (2013)

leading to collaborative conception in the early phases of radical innovation products.

The cryoplane case discussed here is analysed with this motivation to understand the process of creative conception from scratch. Cryoplanes are fuelled by hydrogen (Contreras et al. 1997) or natural gas (Ucler 2013), stored cryogenically in a liquefied phase. Since the expanding aviation industry (Mazraati 2010) is associated with increased fuel consumption (ICAO 2010), it represents a high environmental load (Marquart et al. 2001; Kivits et al. 2010), which contributes to the climate change (Capoccitti et al. 2010). Traditional fuel supply is projected to be limited in the future (Kivits et al. 2010; DOE 2013), where for liquefied gasses are considered along with synthetic biofuels as a solution (Hendricks et al. 2011; ICAO 2009), which are also reducing emissions (Ucler 2013, 2014b). Until now several alternatives have been considered (Daggett et al. 2006; Bradley, Droney 2012), including currently ongoing projects of Boeing (O’Neil 2012) and Airbus Germany (Khandelwal et al. 2013). Early cryoplane technology demonstrators were built in the US (Contreras et al. 1997) and in Russia (AKO 2006). These projects incorporate the adaptation of bulky pressurized tanks into standard aircraft (Fig. 1), where the associated weight and volumetric utilization implications have led to a new concept requirement (Ucler 2013). Consequently, a clean sheet layout definition is targeted here by facilitating brainstorming using the iterative AHP-QFD-AHP approach, as explained in the following section.

\section{QFD, AHP, AHP-QFD and the iterative AHP-QFD-AHP method}

As a total quality management tool (Terninko 1997), Quality Function Deployment (QFD) is a common structured technique (Tidd et al. 2005) for NPD within the concurrent engineering environment. It can be applied across organizational boundaries (Ho, Lin 2012) in conceptual design, where the results of the QFD are computed by weighting factors given as inputs in advance (Bhattacharya et al. 2005). Generally the QFD consists of the house of quality (HOQ) including a matrix with the main requirements in the rows (the whats) and the technical requirements to meet them in the columns (the hows), where the matrix is populated with the appropriate relationships (Ucler et al. 2006). Moreover, the roof of the HOQ gives the dependencies of the technical requirements. An importance rating is associated to each row, i.e. each main requirement. Therefore, when the QFD matrix $Q$ is created for $n$ main requirements and $m$ technical requirements, $\overrightarrow{\mathrm{a}}$ is the input as the importance rating vector of the main requirements; whereas $\vec{b}$ is the output of the HOQ and represents the associated weight of the technical requirements. Mathematically it can be expressed as follows:

$$
\vec{b}=\left(\begin{array}{c}
b_{1} \\
\vdots \\
b_{m}
\end{array}\right)=Q^{\mathrm{T}} \vec{a}=\left(\begin{array}{ccc}
\mathrm{q}_{11} & \cdots & \mathrm{q}_{1 \mathrm{~m}} \\
\vdots & \ddots & \vdots \\
\mathrm{q}_{\mathrm{n} 1} & \cdots & \mathrm{q}_{\mathrm{nm}}
\end{array}\right)^{\mathrm{T}} \times\left(\begin{array}{c}
\mathrm{a}_{1} \\
\vdots \\
\mathrm{a}_{\mathrm{n}}
\end{array}\right)
$$

The input values in $\vec{a}$ might be inconsistent or might not represent all participants' opinions. When the determination of $\vec{a}$ is done using AHP, it is called the AHP-QFD method, where trade-offs and inconsistencies can be easily incorporated (Bhattacharya et al. 2005; Dai, Blackhurst 2012). Among other applications the AHP-QFD is used in for NPD and associated selection problems (Hsiao 2002; Kwong, Bai 2002; Ayag 2005; Liu 2011).

AHP was first introduced in (Saaty 1977) and (Saaty 1980), and it includes all the factors necessary in the decision process in a structured manner by means of problem decomposition into a hierarchy tree with several levels. Pairwise comparisons are then stored in ( $\mathrm{n} \times \mathrm{n}$ ) square matrices for each level. The comparison scale in AHP can be linear, inverse linear or balanced (Ishizaka, Labib 2011). For practicality, Saaty's linear index as in (Saaty 1990) is used here (Table 1), and the pairwise comparison logic is applied within one level only.

The comparison matrix $A$ includes the members $a_{x y}$ with $x=1,2, \ldots, n \wedge y=1,2, \ldots, n$ with the inverse values for $a_{x y}=1 / a_{y x}$. The matrix diagonal is populated with $\mathrm{a}_{\mathrm{xy}}=1$ with $\mathrm{x}=\mathrm{y}=1,2, \ldots, \mathrm{n}$. According to Saaty (1990), the relative weights of criteria and the importance rating of the main requirements in this context can be computed by calculating the normalized eigenvector $\vec{a}$ of the AHP matrix A. $\vec{a}$ can be determined iteratively for the positive reciprocal near consistent matrix A. When the AHP composition is made within a team, this iteration can be used for systematicquestioning for

Table 1. Comparison Scale according to (Saaty 1990)

\begin{tabular}{lcc}
\hline \multicolumn{1}{c}{ Verbal Expression } & $\begin{array}{c}\text { Comparison } \\
\text { Factor }\end{array}$ & Inverse Factor \\
\hline Equal & 1 & 1 \\
\hline Moderate & 3 & $1 / 3$ \\
\hline Strong & 5 & $1 / 5$ \\
\hline Very Strong & 7 & $1 / 7$ \\
\hline Extreme & 9 & $1 / 9$ \\
\hline
\end{tabular}


inconsistencies in the weighting of the QFD input, leading the experts towards creativity via radical innovative NPD. Therefore $\lambda$ is the maximum principle eigenvalue $\left(\lambda_{\text {max }}\right)$ for the given $A \vec{a}=\lambda \vec{a}$. This can be solved easily on numerical basis. Therefore, first matrix $A$ is to be squared delivering $A^{\prime}$, and then all values in row $i$ in $A^{\prime}$ are summed up to give $a_{i}$ of $\vec{a}$ for all $i=1$ to $n$. Afterwards $A^{\prime}$ is set as $A$, and the computation can continue until $\vec{a}$ converges. Since A reflects expert opinions, there can be small errors in the judgment, so the consistency ratio (CR) has to be checked as well (below). According to (Saaty 1990), the consistency index (CI) can deliver the CR, which will be 0.1 , wherefore the RI values can be taken from (Alonso, Lamata 2006), as given in Table 2, and the calculation is as follows:

$$
\mathrm{CI}=\frac{\left(\lambda_{\max }-\mathrm{n}\right)}{(\mathrm{n}-1)} \text { and } \mathrm{CR}=\frac{\mathrm{CI}}{\mathrm{RI}}<0.1 \text {. }
$$

As an extension, fuzzy AHP is also used for alternative evaluations in NPD (Ayag 2005), where, instead of crisp values, fuzzy weightings are used. Consequently, the fuzzy AHP-QFD method was used for the facility location selection (Kumar, Kumanan 2011), supplier selection (Jovanović, Delibašić 2014) or logistics outsourcing (Ho et al. 2012). Since the AHP-QFD approach will deliver a suitable tool to be used on-the-fly during concept development meetings, the computational expensive fuzzy AHP application is not preferred. Also, the fuzzy extent analysis reducing computational efforts in the AHP is not preferred (Chang 1996; Buyukozkan et al. 2004; Bozbura et al. 2007; Yücenur et al. 2011), since it is proven to be incorrect (Yan et al. 2012) and misleading
(Wang et al. 2008), so the standard AHP-QFD approach is used.

In fact, the inconsistency during the AHP-QFD session is analysed here, because it drives the iterations and leads to the questioning of the status quo. This is further increased by incorporating a post QFD evaluation using a stand-alone AHP assessment of the technical requirements (hows) to determine variations from $\vec{b}$, the output of the QFD work, i.e. an iterative AHPQFD-AHP process, is proposed. Therefore, the ( $m \times m)$ pairwise comparison matrix is populated for $m$ technical requirements from the $\mathrm{HOQ}$, and $\overrightarrow{\mathrm{b}^{\prime}}$ is computed using the AHP. Consequently, $\overrightarrow{b^{\prime}}$ is compared with $\vec{b}$. It is expected that these two should be more or less inline with each other. The goal, therefore, is not to create perfectly matching results, but to highlight the inconsistencies again, to drive a review of the requirements and questioning of earlier stages. First of all, the AHP-QFDAHP shall lead to the questioning of the defined weights,

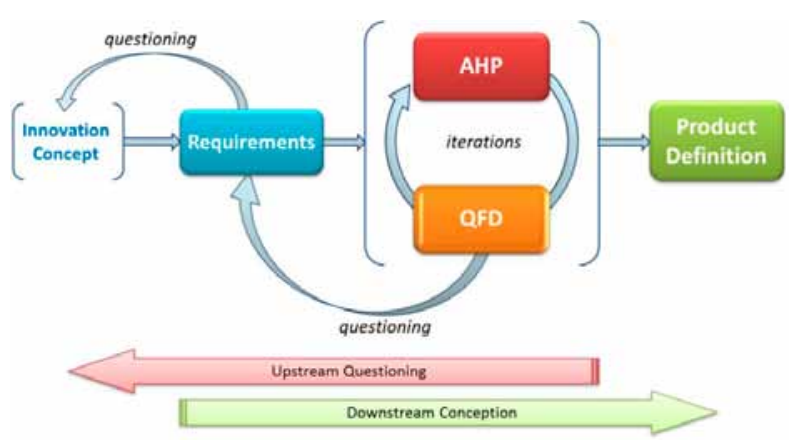

Fig. 2. The iterative AHP-QFD-AHP process

Table 2. RI (n) values from various authors (Alonso, Lamata 2006)

\begin{tabular}{|c|c|c|c|c|c|c|c|c|c|}
\hline & & & & & Author & & & & \\
\hline & $\begin{array}{c}\text { Oak } \\
\text { Ridge }\end{array}$ & Wharton & $\begin{array}{c}\text { Golden } \\
\text { Wang }\end{array}$ & $\begin{array}{l}\text { Lane, } \\
\text { Verdini }\end{array}$ & Forman & Noble & $\begin{array}{l}\text { Tumala, } \\
\text { Wan }\end{array}$ & $\begin{array}{l}\text { Aguaron } \\
\text { et al }\end{array}$ & $\begin{array}{l}\text { Alonso, } \\
\text { Lamata }\end{array}$ \\
\hline Matrices & $\begin{array}{l}\mathrm{n}= \\
100\end{array}$ & $\begin{array}{l}\mathrm{n}= \\
500\end{array}$ & $\begin{array}{c}\mathrm{n}= \\
1000\end{array}$ & $\begin{array}{c}\mathrm{n}= \\
2500\end{array}$ & & $\begin{array}{l}\mathrm{n}= \\
500\end{array}$ & & $\begin{array}{c}\mathrm{n}= \\
100000\end{array}$ & $\begin{array}{c}\mathrm{n}= \\
100000\end{array}$ \\
\hline 3 & 0.382 & 0.58 & 0.5799 & 0.52 & 0.5233 & 0.49 & 0.500 & 0.525 & 0.5245 \\
\hline 4 & 0.946 & 0.90 & 0.8921 & 0.87 & 0.8860 & 0.82 & 0.834 & 0.882 & 0.8815 \\
\hline 5 & 1.220 & 1.12 & 1.1159 & 1.10 & 1.1098 & 1.03 & 1.046 & 1.115 & 1.1086 \\
\hline 6 & 1.032 & 1.24 & 1.2358 & 1.25 & 1.2539 & 1.16 & 1.178 & 1.252 & 1.2479 \\
\hline 7 & 1.468 & 1.32 & 1.3322 & 1.34 & 1.3451 & 1.25 & 1.267 & 1.341 & 1.3417 \\
\hline 8 & 1.402 & 1.41 & 1.3952 & 1.40 & & 1.31 & 1.326 & 1.404 & 1.4056 \\
\hline 9 & 1.350 & 1.45 & 1.4537 & 1.45 & & 1.36 & 1.369 & 1.452 & 1.4499 \\
\hline 10 & 1.464 & 1.49 & 1.4882 & 1.49 & & 1.39 & 1.406 & 1.484 & 1.4854 \\
\hline 11 & 1.576 & 1.51 & 1.5117 & & & 1.42 & 1.433 & 1.513 & 1.5141 \\
\hline 12 & 1.476 & & 1.5356 & 1.54 & & 1.44 & 1.456 & 1.535 & 1.5365 \\
\hline 13 & 1.564 & & 1.5571 & & & 1.46 & 1.474 & 1.555 & 1.5551 \\
\hline 14 & 1.568 & & 1.5714 & 1.57 & & 1.48 & 1.491 & 1.570 & 1.5713 \\
\hline 15 & 1.586 & & 1.5831 & & & 1.49 & 1.501 & 1.583 & 1.5838 \\
\hline
\end{tabular}


then to the upstream questioning of the requirements, and, finally, to the questioning of the desired innovation concept (Fig. 2). In creative brainstorming everything is ensured by forced participation, communication and structured creativity within the group.

\section{The cryoplane application}

A cryoplane is a radical innovation. It represents a big deviation from existing solutions. Therefore, all aspects of operation have to be considered. As a result, the referred concurrent engineering team involved three different groups: flight operations (OPS), represented by commercial pilots; ground management (MNG), represented by civil aviation professionals; engineering (ENG), represented by maintenance, aeronautical design and cryogenics engineers. After the introduction of the concept, all parties were asked what they consider could be important for such a new generation aircraft fuelled with alternative cryogenic fuels. As detailed in (Ucler 2014c), the potential main requirements (whats) were developed and a common list was created:

1. Low weight;

2. Max. safety;

3. High efficiency;

4. High range;

5. High robustness;

6. Low noise;

7. Low volume;

8. Fast bunkering;

9. Long life;

10. Low price;

11. Odourless;

12. Easy to learn.

Due to the input of a cryogenics engineer, the quality of being odourless was eliminated, since one of the prerequisites of such a pressurized cryogenic system is tightness, automatically implying odourless. The learning objective was also eliminated, since it is too early for a conceptual design. Consequently, the AHP matrix was populated as a $(10 \times 10)$ square matrix from the first 10 requirements, and the related pairwise comparisons were assigned in consensus.

In the first iteration high range was overrated in comparison with high efficiency, leading to an inconsistency. This resulted in a reconsideration, arguing that efficiency and range are bonded to each other by optimum cruising speed and the requested mission profile. Moreover, the importance of safety was obvious, so it was scored as extreme against low weight as an aviation reflex. However, during the iterations it was slightly downgraded for this application based on statistical data. It was also noted that the mission profile of the cryoplane has to be considered. Accordingly, a lower speed profile with a higher volume utilization and higher wing thickness was also mutually agreed on in the third iteration. In addition to that, the efficiency and price relationship was also iterated. Pilots defined price as the run cost, whereas the remaining members looked at the whole life cycle cost. Nevertheless, both parties agreed that some compromises can be made given a reduction in the price. This led to a contradiction in the comparison of price with range and efficiency. Consequently, it has been accepted that the price shall include the procurement price of the system, but not the operation costs and the matrix was updated again accordingly. As a result, the final eigenvector $\vec{a}$ indicating the weightings was computed (Fig. 3) after three iterations with $\Delta_{\max }=\% 0.0001$. The consistency ratio of the matrix was determined as $\mathrm{CR}=$ $0.076<0.1$ with $\mathrm{CI}=0.1105$, and the AHP matrix A was found to be consistent.

Subsequently, $\vec{a}$ was used as the input for the QFD work, where the HOQ was modelled based on the excel templates given in (QFD ... 2007). The work group determined the associated technical requirements populating the HOQ (Fig. 4).

After the scoring and computations in the HOQ, the relative weights of the technical requirements were computed as $\vec{b}$. In order to enable an onsite AHP

\begin{tabular}{|c|c|c|c|c|c|c|c|c|c|c|c|}
\hline $10 \times 10$ AHP Matrix & & 1 & 2 & 3 & 4 & 5 & 6 & 7 & 8 & 9 & 10 \\
\hline Low Weight & 1 & 1 & $1 / 7$ & $1 / 3$ & 1 & $1 / 3$ & 1 & 1 & 1 & $1 / 5$ & 3 \\
\hline Max. Safety & 2 & 7 & 1 & 5 & 7 & 3 & 9 & 9 & 9 & 3 & 7 \\
\hline High Range & 3 & 3 & $1 / 5$ & 1 & 1 & $1 / 5$ & 3 & 5 & 7 & 1 & 5 \\
\hline High Efficiency & 4 & 1 & $1 / 7$ & 1 & 1 & $1 / 3$ & 1 & 1 & 5 & 1 & 3 \\
\hline High Robustness & 5 & 3 & $1 / 3$ & 5 & 3 & 1 & 5 & 5 & 7 & 3 & 9 \\
\hline Low Noise & 6 & 1 & $1 / 9$ & $1 / 3$ & 1 & $1 / 5$ & 1 & 1 & 1 & $1 / 3$ & 1 \\
\hline Low Volume & 7 & 1 & $1 / 9$ & $1 / 5$ & 1 & $1 / 5$ & 1 & 1 & 1 & $1 / 3$ & 3 \\
\hline Fast Bunkering & 8 & 1 & $1 / 9$ & $1 / 7$ & $1 / 5$ & $1 / 7$ & 1 & 1 & 1 & 1 & 1 \\
\hline Long Life & 9 & 5 & $1 / 3$ & 1 & 1 & $1 / 3$ & 3 & 3 & 1 & 1 & 3 \\
\hline Low Price & 10 & $1 / 3$ & $1 / 7$ & $1 / 5$ & $1 / 3$ & $1 / 9$ & 1 & $1 / 3$ & 1 & $1 / 3$ & \\
\hline
\end{tabular}

Fig. 3. The AHP Matrix with the associated pairwise comparisons

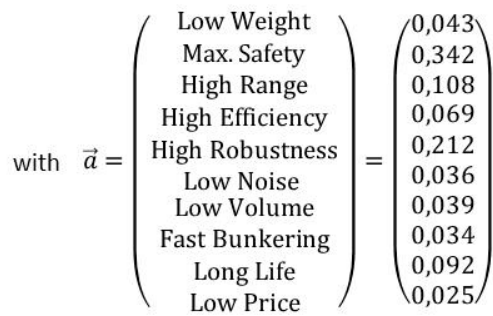




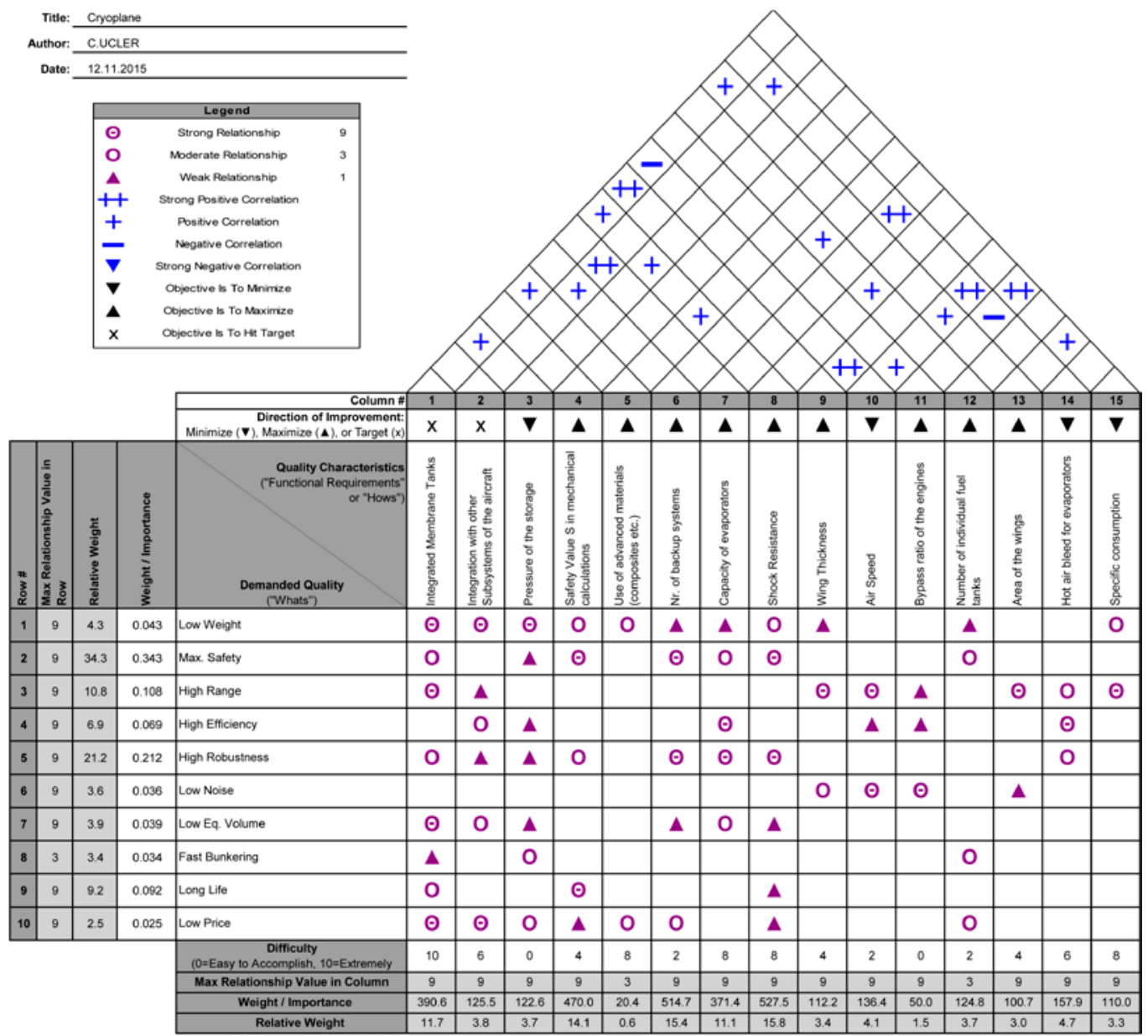

Fig. 4. The HOQ for the Cryoplane

Table 3. Weight factors and associated ranking of technical requirements in the first iteration

\begin{tabular}{|c|c|c|c|c|c|c|c|}
\hline $\begin{array}{l}\text { Nr. } \\
\text { (j) }\end{array}$ & Technical Requirement & $\begin{array}{l}\text { Relative } \\
\text { Weight } \\
\left(\mathbf{b}_{\mathbf{j}}\right)\end{array}$ & Ranking & $\begin{array}{l}\text { Updated } \\
\text { Comparison } \\
\text { Value }\left(\mathbf{b}_{\mathbf{j}}\right)^{\prime}\end{array}$ & $\begin{array}{l}\text { Post AHP } \\
\text { Weight } \\
\left(\mathbf{b}_{\mathbf{j}}\right)\end{array}$ & $\begin{array}{l}\text { Post } \\
\text { AHP } \\
\text { Rank }\end{array}$ & Delta \\
\hline 1. & Integrated Membrane Tanks & 11.71 & 4 & 13.28 & 3.16 & 9 & $-76 \%$ \\
\hline 2. & Integration with other Subsystems & 3.76 & 8 & 4.26 & 9.05 & 4 & $112 \%$ \\
\hline 3. & Pressure of the storage & 3.68 & 10 & 4.17 & 3.72 & 8 & $-11 \%$ \\
\hline 4. & Safety Value $S$ in mechanical calculations & 14.10 & 3 & 15.98 & 16.25 & 3 & $2 \%$ \\
\hline 5. & Use of advanced materials & 0.61 & 15 & - & - & - & - \\
\hline 6. & Nr. of backup systems & 15.43 & 2 & 17.49 & 7.58 & 5 & $-57 \%$ \\
\hline 7. & Capacity of evaporators & 11.14 & 5 & 12.63 & 17.86 & 2 & $41 \%$ \\
\hline 8. & Shock Resistance & 15.82 & 1 & 17.93 & 19.53 & 1 & $9 \%$ \\
\hline 9. & Wing Thickness & 3.36 & 11 & - & - & - & - \\
\hline 10. & Air Speed & 4.09 & 7 & 4.64 & 4.91 & 6 & $6 \%$ \\
\hline 11. & Bypass ratio of the engines & 1.50 & 14 & - & - & - & - \\
\hline 12. & Number of individual fuel tanks & 3.74 & 9 & 4.24 & 4.26 & 7 & $0 \%$ \\
\hline 13. & Area of the wings & 3.02 & 13 & - & - & - & - \\
\hline 14. & Hot air bleed for evaporators & 4.74 & 6 & 5.37 & 13.68 & 10 & $155 \%$ \\
\hline \multirow[t]{2}{*}{15.} & Specific consumption & 3.30 & 12 & - & - & - & - \\
\hline & & Sum $=1$ & & Sum $=100$ & & & \\
\hline
\end{tabular}




\begin{tabular}{|c|c|c|c|c|c|c|c|c|c|c|c|c|}
\hline Post QFD AHP Matrix & & & & & & & & & & & & $\begin{array}{l}\text { Normalized } \\
\text { Principal } \\
\text { Eigenvector }\end{array}$ \\
\hline & & 1 & 2 & 3 & 4 & 5 & 6 & 7 & 8 & 9 & 10 & \\
\hline Integrated Membrane Tanks & 1 & 1 & $1 / 5$ & 1 & $1 / 3$ & $1 / 5$ & $1 / 7$ & $1 / 7$ & 1 & 1 & $1 / 3$ & $3,16 \%$ \\
\hline Integration with other Subsystems of the aircraft & 2 & 5 & 1 & 3 & 1 & 1 & $1 / 5$ & $1 / 5$ & 3 & 3 & $1 / 3$ & $9,05 \%$ \\
\hline Pressure of the storage & 3 & 1 & $1 / 3$ & 1 & $1 / 5$ & 1 & $1 / 3$ & $1 / 3$ & $1 / 3$ & $1 / 3$ & $1 / 3$ & $3,72 \%$ \\
\hline Safety Value S in mechanical calculations & 4 & 3 & 1 & 5 & 1 & 5 & 1 & 1 & 3 & 5 & 1 & $16,25 \%$ \\
\hline $\mathrm{Nr}$. of backup systems & 5 & 5 & 1 & 1 & $1 / 5$ & 1 & $1 / 3$ & $1 / 3$ & 1 & 3 & 1 & $7,58 \%$ \\
\hline Capacity of evaporators & 6 & 7 & 5 & 3 & 1 & 3 & 1 & 1 & 3 & 3 & 1 & $17,86 \%$ \\
\hline Shock Resistance & 7 & 7 & 5 & 3 & 1 & 3 & 1 & 1 & 5 & 5 & 1 & $19,53 \%$ \\
\hline Air Speed & 8 & 1 & $1 / 3$ & 3 & $1 / 3$ & 1 & $1 / 3$ & $1 / 5$ & 1 & 1 & $1 / 3$ & $4,91 \%$ \\
\hline Number of individual fuel tanks & 9 & 1 & $1 / 3$ & 3 & $1 / 5$ & $1 / 3$ & $1 / 3$ & $1 / 5$ & 1 & 1 & $1 / 3$ & $4,25 \%$ \\
\hline Hot air bleed for eva porators & 10 & 3 & 3 & 3 & 1 & 1 & 1 & 1 & 3 & 3 & 1 & $13,68 \%$ \\
\hline
\end{tabular}

Fig. 5. The Post QFD AHP Computation

assessment, a rank reduction was done, eliminating technical requirements after the 10th rank. The weighting of the requirements from 11 to 15 was distributed to the other requirements depending on their importance per QFD. This new set is called $\overrightarrow{b^{\prime}}$. Subsequently, the post QFD weights were computed by running an AHP for the (10x10) matrix of technical requirements delivering $\overrightarrow{\mathrm{b}}$ (Fig. 5). The difference between $\overrightarrow{b^{\prime}}$ and $\overrightarrow{b^{\prime \prime}}$ is designated as Delta (Table 3).

Since the post AHP computation of the technical requirements was found to be consistent with $\mathrm{CR}=0.073$, the QFD inputs were questioned in line with the AHPQFD-AHP methodology. Therefore, the AHP ranking was used to visualize the data easier. The target of the comparison was clearly not to achieve totally similar results in the QFD and post AHP. Questioning the status quo, it was seen that hot air bleed for evaporators was underestimated in the first line. This was explained by the QFD score for high range and its associated weight / importance. This was also noticed in the roof of the HOQ, showing a strong correlation with the air speed and with the thickness of the wings. It was also seen that the capacity of the evaporators had to be weighted more, which led to the idea that supplementary heat sources shall be incorporated to enhance the fuel conditioning process. This statement was also supported with the higher post AHP ranking of integration with other subsystems of the aircraft. The last significant deviation obtained by post AHP was that the integrated membrane tanks were weighted less than initially anticipated.

\section{Discussion}

It was shown that the usage of an iterative AHP-QFDAHP supports the product conception in two ways: iterative questioning of the weighting of the main requirements and upstream questioning by post AHP. The iterations for the AHP computation of the importance vector $\vec{a}$ for the HOQ enabled all experts to understand the correct definitions associated to the requirements in the same way and to have an overview of the other dimensions' perceptions. Since all representatives had to achieve a consensus in the pairwise comparisons, concurrency was forced with this information exchange. This led to an understanding of the real requirements, e.g. in the first line it was determined that the requirements for the preparation of conditioned gas as fuel are more important for cryoplanes rather than ordinary aeronautical constraints. This was reflected in different aspects, such as the hot air bleed for evaporators, capacity of the evaporators, and the integration with other systems, which were rated higher in post AHP. This in fact resulted in a number of the back-up systems being estimated as a less important factor in the comparison. Indeed, later literature analysis indicated a patent of Airbus facilitating the air conditioning system as a heat source for the cryogenic system and vice versa (Airbus 2012). In short, this method allowed including unpredicted aspects during the session, indicating a cognitive collaboration.

This led to the requirement for the engine to be incorporated in the cryoplane preliminary design. It was shown that the cryoplane development is not a standard system integration job, where existing subsystems can be integrated, but is a radical innovative product with the need of building the aircraft around the cryogenic system. As a result, this indicated the basic research areas as well as supporting technology road mapping.

Apart from this, the interconnections in the roof of the HOQ were questioned within the iterations. This came up analytically when questioning the flight envelope. Parameters such as consumption, manoeuvrability, and flight envelope were looked at in detail. In fact, these details were not included in the HOQ at first, but the questioning process of post AHP accomplished a creative thinking session where a totally new concept was preferred - a lower speed jet or turboprop aircraft 
with thicker wings incorporating the available volume in the wings. Furthermore, a radical blended wing body concept was proposed during the sessions, where the pressurized tanks can support the fuselage in an integrated manner. This is an untraditional approach and a highly creative outcome. Moreover, the integration of heat from sources such as engine exhaust, air conditioning or possible usage in combination with fuel cells was proposed, which again indicates innovation.

The interrelationships between the technical requirements as indicated in the roof of the HOQ have to be mentioned as well. During the case study they were not included in the AHP evaluation. In fact, a good design has the minimum interaction among its variables with the least information (Park 2007), but for sophisticated products, it is unavoidable. Therefore, analytical network processes (ANP) could be used to include interrelationships (Yücenur et al. 2011). However, since the post AHP here is just a tool to drive the questioning rather than to provide a basis for weighting, a classical AHP is used for simplicity. Nevertheless, it should be noted that it is worth to have further research on the interrelationships and how they can be incorporated into this method.

In summary, the design envelope of a cryoplane was determined, and a product concept was drawn successfully making use of the extended iterative AHP-QFD-AHP approach. It was noticed that the limited set of requirements using this method lead to further requirements during the application. These new requirements were not used to extend the QFD matrix, but they were noticed as creative outcomes of the brainstorming session.

\section{Conclusions}

An iterative AHP-QFD-AHP approach providing an analytical approach for collaborative creativity and leading to innovative product conception is proposed. This proposed methodology differs from standard AHPQFD applications in two basic elements. First of all, the AHP application for the determination of QFD weights of the Hows is not post processing questionnaire data, but includes a team of experts to generate the assessment together in an iterative session. Second, there is a post AHP application to review and to check the output of the QFD. As a result, this methodology is used as a real time tool involving the participants in an upstream questioning process, increasing the participation, and hence evaluating different dimensions, which leads to creativity in the downstream product conception.

Consequently, the extended iterative AHP-QFDAHP approach can be used in front-end product conception, where high levels of innovation are required. This was demonstrated here with the cryoplane concept development work, which resulted in an environmentally green, lower speed aircraft built around the cryogenic system, using it as an integrated part in both fuselage and subsystems. The main challenge is identified as the conditioning of the cryogenic fuel.

Future work can examine the correlation levels of the post AHP and the QFD outcome in existing AHPQFD applications to evaluate mathematical correlation models. The interrelationships on the roof of the HOQ were used in the comparison process only qualitatively; therefore, quantitative models involving the roof could be developed as well.

\section{References}

Airbus. 2012. Air conditioning system for an aircraft. Patent Application of Airbus Operations GmbH, US 20120240599 A1, Application number: 13/424,966.

AKO. 2006. Tupolev's alternative, AKO Journal 3: 78-79 [online], [cited 10 June 2013]. Available from Internet: http:// www.be-and-co.com/ako_pdf/ako030678.pdf

Alonso, J. A.; Lamata, M. T. 2006. Consistency in the analytic hierarchy process: a new approach, International Journal of Uncertainty, Fuzziness and Knowledge-Based Systems 14(4): 445-459. https://doi.org/10.1142/S0218488506004114

Ayag, Z. 2005. A fuzzy AHP-based simulation approach to concept evaluation in a NPD environment, IIE Transactions 37(9): 827-842. https://doi.org/10.1080/07408170590969852

Bhattacharya, A.; Sarkar, B.; Mukherjee, S. K. 2005. Integrating AHP with QFD for robot selection under requirement perspective, International Journal of Production Research 43(17): 3671-3685. https://doi.org/10.1080/00207540500137217

Borgianni, Y.; Rotini, F. 2012. Innovation trajectories within the support of decisions: insights about s-curve and dominant design models, International Journal of Innovation Science 4(4): 259-267. https://doi.org/10.1260/1757-2223.4.4.259

Bozbura, F. T.; Beskese, A.; Kahraman, C. 2007. Prioritization of organizational capital measurement indicators using fuzzy AHP, Expert Systems with Applications 32(4): 11001112. https://doi.org/10.1016/j.eswa.2006.02.006

Bradley, M. K.; Droney, C. K. 2012. Subsonic ultra green aircraft research, phase ii: $n+4$ advanced concept development, technical report prepared for Langley Research Center under Contract NNL11AA00T, Report Number NASA/CR-2012217556. National Aeronautics and Space Administration, Langley Research Center.

Buyukozkan, G.; Kahraman, C.; Ruan, D. 2004. A fuzzy multi-criteria decision approach for software development strategy selection, International Journal of General Systems 33(2-3): 259-280.

https://doi.org/10.1080/03081070310001633581

Capoccitti, S.; Khare, A.; Mildenberger, U. 2010. Aviation industry - mitigating climate change impacts through technology and policy, Journal of Technology Management \& Innovation 5(2): 66-75. https://doi.org/10.4067/S0718-27242010000200006

Chang, D. Y. 1996. Applications of the extent analysis method on fuzzy AHP, European Journal of Operational Research 95: 649-655. https://doi.org/10.1016/0377-2217(95)00300-2

Contreras, A.; Yiğit, S.; Ozay K.; Veziroglu, T. N. 1997. Hydrogen as aviation fuel: a comparison with hydrocarbon fuels, International Journal of Hydrogen Energy 22(10/11): 105-1060. https://doi.org/10.1016/s0360-3199(97)00008-6 
Daggett, D.; Hadaller, O.; Hendricks, R.; Walther, R. 2006. Alternative fuels and their potential impact on aviation, NASA STI Report, NASA/TM 2006-214365, in 25th Congress of the International Council of the Aeronautical Sciences (ICAS), 3-8 September 2006, Hamburg, Germany.

Dai, J.; Blackhurst, J. 2012. A four-phase AHP-QFD approach for supplier assessment: a sustainability perspective, International Journal of Production Research 50(19): 5474-5490. https://doi.org/10.1080/00207543.2011.639396

De Florio, F. 2006. Airworthiness: an introduction to aircraft certification: a guide to understanding JAA, EASA, and FAA Standards. Oxford: Butterworth-Heinemann.

DOE. 2013. US Department of Energy, Multi-Year Research, Development, and Demonstration Plan, Planned program activities for 2011-2020, Technical Report [online], [cited 17 December 2014]. Available from Internet: http://wwwl. eere.energy.gov

DLR. 2015. CPACS - a common language for aircraft design [online], [cited 30 August 2015]. Available from Internet: https://software.dlr.de/p/cpacs

Fixson, S. K.; Marion, T. J. 2012. Back-loading: a potential side effect of employing digital design tools in new product development, Journal of Product Innovation Management 29(S1): 140-156.

https://doi.org/10.1111/j.1540-5885.2012.00959.x

Florén, H.; Frishammar, J. 2012. From preliminary ideas to corroborated product definitions: managing the front end of new product development, California Management Review 54(4): 20-43. https://doi.org/10.1525/cmr.2012.54.4.20

Ho, Y. C.; Lin, C. H. 2012. A QFD- and concurrent engineering-based outsourced product development methodology for ODM customers, Total Quality Management 23(10): 1153-1169. https://doi.org/10.1080/14783363.2012.669559

Hendricks, R. C.; Bushnell, D. M.; Shouse, D. T. 2011. Aviation fueling: a cleaner, greener approach, International Journal of Rotating Machinery. Article ID 782969.

https://doi.org/10.1155/2011/782969

Ho, W.; He, T.; Lee, C. K. M.; Emrouznejad, A. 2012. Strategic logistics outsourcing: An integrated QFD and fuzzy AHP approach, Expert Systems with Applications 39(12): 1084110850. https://doi.org/10.1016/j.eswa.2012.03.009

Hsiao, S. W. 2002. Concurrent design method for developing a new product, International Journal of Industrial Ergonomics 29(1): 41-55. https://doi.org/10.1016/S0169-8141(01)00048-8

ICAO. 2009. A Summary of research and perspectives. Technical Report, in ICAO Workshop on Aviation and Alternative Fuels WAAF 2009, February 2009, Montreal, Canada.

ICAO. 2010. Present and future aircraft noise and emissions trends, in the ICAO Assembly $37^{\text {th }}$ Session, Agenda Item 17: Environmental protection, A37-WP/26 EX/9 21/7/10.

Ishizaka, A.; Labib, A. 2011. Review of the main developments in the analytic hierarchy process, Expert Systems with Applications 38(11): 14336-14345.

https://doi.org/10.1016/j.eswa.2011.04.143

Iyer, R.; Laplaca, P. J.; Sharma, A. 2006. Innovation and new product introductions in emerging markets: strategic recommendations for the Indian market, Industrial Marketing Management 35(3): 373-382.

https://doi.org/10.1016/j.indmarman.2005.02.007

Jovanović, B.; Delibašić, B. 2014. Application of integrated QFD and fuzzy AHP approach in selection of suppliers, Management 72: 25-35.

https://doi.org/10.7595/management.fon.2014.0018
Khandelwal, B.; Karakurt, A.; Sekaran, P. R.; Sethi, V.; Singh, R. 2013. Hydrogen powered aircraft: The future of air transport, Progress in Aerospace Sciences 60: 45-59. https://doi.org/10.1016/j.paerosci.2012.12.002

Kivits, R.; Charles, M. B.; Ryan, N. 2010. A post-carbon aviation future: Airports and the transition to a cleaner aviation sector, Futures 42(3): 199-211. https://doi.org/10.1016/j.futures.2009.11.005

Kumar, K.; Kumanan, S. 2011. An integrated fuzzy QFD and AHP approach for facility location selection, IUP Journal of Supply Chain Management 8(4): 30-41.

Kwong, C. K.; Bai, H. 2002. A fuzzy AHP approach to the determination of importance weights of customer requirements in quality function deployment, Journal of Intelligent Manufacturing 13(5): 367-377. https://doi.org/10.1023/A:1019984626631

Leenders, R. T. A. J.; Van Engelen, J. M. L.; Kratzer, J. 2007. Systematic design methods and the creative performance of new product teams: do they contradict or complement each other?, Journal of Product Innovation Management 24(2): 166-179. https://doi.org/10.1111/j.1540-5885.2007.00241.x

Liu, H. T. 2011. Product design and selection using fuzzy QFD and fuzzy MCDM approaches, Applied Mathematical Modelling 35: 482-496. https://doi.org/10.1016/j.apm.2010.07.014

Marquart, S.; Sausen, R.; Ponater, M.; Grewe, V. 2001. Estimate of the climate impact of cryoplanes, Aerospace Science and Technology 5(1): 73-84. https://doi.org/10.1016/S1270-9638(00)01084-1

Mas, F.; Menéndez, J. L.; Oliva, M.; Ríos, J. 2013. Collaborative engineering: an airbus case study, Procedia Engineering 63: 336-345. https://doi.org/10.1016/j.proeng.2013.08.180

Mazraati, M. 2010. World aviation fuel demand outlook, OPEC Energy Review 34(1): 42-72. https://doi.org/10.1111/j.1753-0237.2010.00174.x

O'Neil, P. 2012. Boeing High Altitude Long Endurance (HALE) UAS. Power Point Presentation of Boeing Defense, Space \& Security [online], [cited 17 December 2014]. Available from Ineternet: www.boeing.com

Park, G. J. 2007. Analytic methods for design practice. London: Springer.

QFD Online. 2007. Traditional house of quality. Excel template, version 2.0.346.0, [online], [cited 01 March 2014]. Available from Internet:www.qfdonline.com

Saaty, T. L. 1977. A scaling method for priorities in hierarchical structures, Journal of Mathematical Psychology 15: 234-281. https://doi.org/10.1016/0022-2496(77)90033-5

Saaty, T. L. 1980. The analytic hierarchy process. New York: McGraw-Hill.

Saaty, T. L. 1990. How to make a decision: the analytic hierarchy process, European Journal of Operations Research 48: 9-26. https://doi.org/10.1016/0377-2217(90)90057-I

Safavi, E. 2013. Collaborative Multidisciplinary Design Optimization: A Framework Applied on Aircraft Systems and Industrial Robots. Thesis, No. 1585. Linköping Studies in Science and Technology. Linköping, Sweden: Linköping University.

Terninko, J. 1997. Step-by-step QFD: customer-driven product design. $2^{\text {nd }}$ ed. CRC Press.

Tidd, J.; Bessant, J.; Pavitt, K. 2005. Managing innovation: integrating technological, market and organizational change. $3^{\text {rd }}$ ed. John Wiley \& Sons, Ltd.

$\mathrm{Tu}, \mathrm{C} .2009$. A multilevel investigation of factors influencing creativity in NPD teams, Industrial Marketing Management 38: 119-126. https://doi.org/10.1016/j.indmarman.2007.10.001 
Ucler, C.; Vayvay, O.; Cobanoglu, E. 2006. Customer-focused product development and a case study in Turkish refrigerator market, Istanbul Commerce University Journal of Science 2: 81-97.

Ucler, C. 2013. LNG as an alternative aviation fuel: Incorporatıng membrane type cryogenic wing tanks with a central cryogenic pressure vessel for airborne LNG storage and fuelling, in the $7^{\text {th }}$ Ankara International Aerospace Conference, AIAC 2013-106, 11-13 September, 2013, Ankara, Turkey.

Ucler, C. 2014a. Involvement of the notifying body in the innovative development environment: lessons learnt from the development of green alternative cryogenic fuelling systems in multinational work groups, in the $20^{\text {th }}$ ICE IEEE Technology Management Europe Conference, 23-25 June 2014, Bergamo, Italy.

Ucler, C. 2014b. Evaluation of alternative cryogenic green propulsion systems in terms of aviation infrastructure, Air Transport Research Society, in the ATRS 2014 World Conference, 17-20 July 2014, Bordeaux, France. No. 127, 34 p.
Ucler, C. 2014c. Special requirements of aircraft with alternative cryogenic fuelling and determination of an innovative design envelope using QFD-AHP, in HITEK 2014. 18-19 June 2014, Istanbul, Turkey.

Wang, Y. M.; Luo, Y.; Hu a, Z. 2008. On the extent analysis method for fuzzy AHP and its applications, European Journal of Operational Research 186: 735-747. https://doi.org/10.1016/j.ejor.2007.01.050

Yan, L. J.; Li, Z. B.; Xi, W. K.; Yuan, X. Y. 2012. Group-based product scheme-screening decision method based on fuzzy AHP and evidential reasoning theory, International Journal of Production Research 50(1): 133-159. https://doi.org/10.1080/00207543.2011.571450

Yücenur, G. N.; Vayvay, O.; Demirel, N. C. 2011. Supplier selection problem in global supply chains by AHP and ANP approaches under fuzzy environment, International Journal of Advanced Manufacturing Technologies 56: 823-833. https://doi.org/10.1007/s00170-011-3220-y 